\title{
Lateral Root Traits of Taxodium Hybrid 'Zhongshanshan 406' in Response to Drought Stress
}

\author{
Qin Shi, Yunlong Yin, Zhiquan Wang, Wencai Fan, Jinbo Guo, \\ and Jianfeng Hua ${ }^{1}$ \\ Institute of Botany, Jiangsu Province and Chinese Academy of Sciences, \\ Nanjing 210014, Jiangsu, China
}

Additional index words. lateral roots, physiology, morphology, water deficit

\begin{abstract}
Roots are vital organs for resource uptake. However, the knowledge regarding the extent by which responses in roots influence plant resistance is still poorly known. In this study, we examined the morphological and physiological responses of lateral roots of Taxodium hybrid 'Zhongshanshan 406' (Taxodium mucronatum ${ }_{+}$and Taxodium distichum ${ }^{\uparrow}, T$. 406) to 8 (DS-8) and 12 days (DS-12) drought. Control plants (CK-8 and CK-12) were well-watered throughout the experiment. Results indicated that drought resulted in significantly decreased root length, surface area, volume, and biomass and a relatively high death rate of roots $(>2 \mathrm{~mm})$. Specific root length (SRL) and specific root surface area (SRA) of drought-stressed $T .406$ plants were reduced to enhance resource uptake. Meanwhile, root relative water content (RWC) of $T .406$ plants in CK-12 treatment was 5.81 times of those in DS-12 treatment. Under drought stress and root superoxide dismutase and ascorbic acid (ASA) activities, proline and hydrogen peroxide $\left(\mathrm{H}_{2} \mathrm{O}_{2}\right)$ contents consistently increased to benefit the elimination of $\mathrm{O}_{2}{ }^{-}$. At the ultrastructural level, the organelle structure of $T .406$ plant root tip was visibly damaged because of dehydration. The nucleus swelled and then exhibited uncommon features of disorganization and disruption. In short, our results provided substantial information about lateral root traits of $T$. 406 plants in response to drought stress, which is crucial to improve the drought resistance of Taxodium hybrid in the future breeding.
\end{abstract}

Over the large area of the Earth's surface, drought is a major factor limiting plant productivity (Rowland et al., 2015). Tree roots play a key role in the drought tolerance but are relatively understudied compared with components of aboveground plant. Forest dieback as a result of increasing drought intensities has frequently been reported worldwide, from semiarid areas in Australia to Algeria in North Africa, and to Costa Rica in Latin America (Allen et al., 2010; Hartmann et al., 2015).

Given the impacts of drought, past causes and the possible mechanisms by which drought could occur in the future have received substantial attention. Studies have been implemented to explain tree death during drought from a physiological perspective (Allen et al., 2010; Diffenbaugh and Scherer, 2011). Plants can minimize water loss through inhibited transpiration by reducing leaf area and $g_{\mathrm{S}}$, which comes at a cost of reduced photosynthesis. Currently, there are clear evidences that drought stress reduces

Received for publication 7 Aug. 2017. Accepted for publication 17 Jan. 2018.

This work was supported by the Program of Innovation Capacity Construction of Jiangsu Province (BM2015019), the National Natural Science Foundation of China (31570593), and the Jiangsu Agriculture Science and Technology Innovation Fund (JASTIF) [CX(16)1005].

${ }^{1}$ Corresponding author. E-mail: jfhua2009@gmail. com. photosynthetic capacity and then inhibits plant productivity (Allen et al., 2010). Plant roots respond to environmental stresses by undergoing plastic morphological and physiological alteration (Doussan et al., 1999). Leaf transpiration drives water absorption through the root system, and root characteristics eventually determine plant access to water. Lateral roots are considered the main entrance point for water absorption, which might be greatly influenced by the traits of lateral root tips (Doussan et al., 1999). Ito et al. (2006) draw the conclusion that variations in the length of first-order lateral roots in responses to drought stress may help distribute their tips thoroughly in the soil. Thus, a potential xeromorphic response of plant root to reduced soil water availability is necessary to be examined.

The genus Taxodium is valuable for restoring degraded coastal areas, urban landscapes, and other greening projects (Creech et al., 2011). In China, Taxodium hybrid 'Zhongshanshan 406' (T. 406) is an accepted term that describes a hybrid selection created by a cross between $T$. mucronatum and $T$. distichum. The field afforestation of T. 406 plants from 2010 indicated heterobeltiosis in growth rate and environmental adaptation (Wu et al., 2016). T. 406 plants are insectresistant and, therefore, considered promising in future forestry efforts in China. Although recent selection for drought resistance in Taxodium hybrids has primarily been based on physiological acclimation in leaf under drought condition, the mechanisms in lateral roots by which Taxodium hybrids achieve potential high vitality under drought are not well understood.

For root measurements, Kano et al. (2011) used mainly root length as a significant parameter because of its determination of water and nutrient uptake. This study investigates several lateral root characteristics in T. 406 plants, aiming to detect adaptive responses of the root system to a decrease in water availability. Information about the ability of $T$. 406 plants to alter root traits under water stress could result in strategies of improved breeding for drought resistance in Taxodium hybrids.

\section{Materials and Methods}

The experiment was conducted in a greenhouse located in Nanjing Botanical Garden $\left(32^{\circ} 3^{\prime} \mathrm{N}, 118^{\circ} 49^{\prime} \mathrm{E}\right)$. Rooted cuttings of 1-year-old T. 406 plants were grown in plastic pots of $7.2 \mathrm{~L}$ ( $23 \mathrm{~cm}$ upper diameter, $15 \mathrm{~cm}$ basal diameter, and $22 \mathrm{~cm}$ high) containing $3: 1: 1(\mathrm{v} / \mathrm{v} / \mathrm{v})$ clay, vermiculite, and perlite under natural condition from June to Aug. 2016. They were allowed to acclimate for $70 \mathrm{~d}$ before imposing the drought treatment. After last watering on 23 Aug., 16 plants of similar growth (average $62.3 \mathrm{~cm}$ in height, $8.45 \mathrm{~mm}$ in basal diameter) were transferred to a greenhouse. A 50\% sunshade net with uniform pore size was placed at the top of the greenhouse to avoid direct sunlight exposure. Control treatments were watered daily to previous pot capacity throughout the experiment. On days 8 and 12 , four plants of each control treatment were separately taken from the respective pots and were set as CK-8 and CK-12 treatments, respectively. Droughtstressed plants did not receive irrigation and were sampled on 8 (DS-8) and $12 \mathrm{~d}$ (DS-12), respectively. Each treatment included four replications. A split-plot in a randomized complete block was used.

Temperature and relative humidity of the greenhouse were measured three times a day ( $0800 \mathrm{HR}, 1200 \mathrm{HR}$, and $1600 \mathrm{HR})$. Soil water content was determined by oven-drying at $105{ }^{\circ} \mathrm{C}$ in DS- 8 and DS- 12 treatments after sampling (Hardie et al., 2014). During the experiment, mean daily temperature and relative humidity of greenhouse were $30.1^{\circ} \mathrm{C}$ and $52.6 \%$, respectively. On the first day after watered to pot capacity, soil water content was $\approx 26.2 \%$ in all pots. Then, the water content consecutively decreased in drought-stressed pots with drought duration. In DS-8 treatment, soil water content declined to $9.1 \%$ and $T .406$ plants became wilt. In DS-12 treatment, water content reduced to $6.0 \%$ and the plants exhibited obvious wilting phenomenon with one-third of the leaves wilting irreversibly.

Biomass and root morphology analysis. Plant height and basal diameter were measured with a tapeline and a vernier caliper, respectively. Then, plants were separated into leaf, stem, and root and well washed. Lateral roots were spread apart on a water 
layer in a transparent tray $(32 \mathrm{~cm} \times 24 \mathrm{~cm})$ for scan. The Epson scanning system was set at professional mode with reflective light at a resolution of 400 DPI. Thereafter, root images were analyzed for morphological traits of total length, surface area, volume, and their distribution in the root $n$ diametric class, where $n$ is $0-1,1-2$, and $>2 \mathrm{~mm}$, by WinRHIZO software (V5.0; Regent Instruments, Quebec, Canada) (Cavelier et al., 1992). After that, leaf, stem, and root were firstly dried at $105^{\circ} \mathrm{C}$ for $30 \mathrm{~min}$, then further dried at $75^{\circ} \mathrm{C}$ for $48 \mathrm{~h}$ to obtain constant dry weight (DW). Specific root length and SRA were calculated as the ratio of total length/ root DW and surface area/root DW, respectively. Root density was calculated as the ratio of root DW/volume. The root/shoot ratio was the result of underground parts/ aboveground parts.

Root vigor, $R W C$, nitrogen, and phosphorus analysis. Root vigor was measured according to the triphenyltetrazolium chloride (TTC) method (Liu et al., 2008). Before TTC incubation, $1.00 \mathrm{~g}$ roots were washed thoroughly with distilled water for $10 \mathrm{~min}$ and placed in $10 \mathrm{~mL}$ of TTC reaction solution $\left(0.5 \%\right.$ TTC in $0.06 \mathrm{~mol} \cdot \mathrm{L}^{-1}$ phosphatic buffer, $\mathrm{pH}$ 7.4) for $3 \mathrm{~h}$ at $37^{\circ} \mathrm{C}$ in the dark. Then $2 \mathrm{~mL}$ of $1 \mathrm{~mol} \cdot \mathrm{L}^{-1} \mathrm{H}_{2} \mathrm{SO}_{4}$ was added to the tube to stop the reaction. The TTC solution was drained. Roots were ground and extracted with $10 \mathrm{~mL}$ of ethyl acetate and then the absorbance was read at $485 \mathrm{~nm}$. For root RWC, selected fresh roots were weighed (FW) and then floated on distilled water in petri dishes for $24 \mathrm{~h}$ to regain turgidity (Rouphael et al., 2008). After that, roots were reweighed [turgid weight (TW)] without excess water and DW was measured. Root RWC was calculated as (FW DW/TW - DW) $\times 100 \%$.

Pulverized root samples of $0.10 \mathrm{~g}$ were digested in a digestion oven in concentrated $\mathrm{H}_{2} \mathrm{SO}_{4}-\mathrm{H}_{2} \mathrm{O}_{2}$ with mixed catalyst and then gradually heated to $400{ }^{\circ} \mathrm{C}$ until the contents became colorless. The extracting solution was analyzed with the Kjeldahl method (Kirk, 1950) and the Mo-Sb colorimetric method (Mel'Tser, 1960) to determine total nitrogen (TN) and total phosphorus (TP), respectively.

Proline, abscisic acid (ABA), and $\mathrm{H}_{2} \mathrm{O}_{2}$ determination. Fresh root tissue $(0.20 \mathrm{~g})$ was macerated in $3 \%$ aqueous sulfosalicylic acid and heated at $100{ }^{\circ} \mathrm{C}$ for $10 \mathrm{~min}$ for proline analysis. The contents of proline were then determined by the acid-ninhydrin reagent method on a FW basis (Bates et al., 1973). A sample of $0.20 \mathrm{~g}$ of root tip tissue was macerated in liquid nitrogen and $5 \mathrm{~mL}$ of $80 \%(\mathrm{v} / \mathrm{v})$ methanol was added. The extract was subsequently centrifuged at $4000 \mathrm{rpm}$ at $4{ }^{\circ} \mathrm{C}$. Abscisic acid was measured without further purification by an ELISA (ELISA; Jiancheng Institute of Biology and Engineering, Nanjing, China) using a monoclonal antibody. Absorbance values were recorded by a microplate reader (Bio-Tek; Winooski, VT) at $450 \mathrm{~nm}$. The content of $\mathrm{H}_{2} \mathrm{O}_{2}$ was analyzed with an $\mathrm{H}_{2} \mathrm{O}_{2}$ assay kit (S0038; Beyotime). After adding the $\mathrm{H}_{2} \mathrm{O}_{2}$ lysate, test tubes with $50 \mu \mathrm{L}$ sample solution were placed at room temperature for $30 \mathrm{~min}$ and then measured immediately with a microplate reader at a wavelength of $560 \mathrm{~nm}$.

Antioxidase activities and ASA analysis. Each $0.2 \mathrm{~g}$ fresh root tip tissue was ground under ice-cold conditions with $5 \mathrm{~mL}$ phosphate buffer $(\mathrm{pH} 7.8)$ and then centrifuged at the rotation speed of $12,000 \mathrm{rpm}$ for $20 \mathrm{~min}$ at $4{ }^{\circ} \mathrm{C}$. Superoxide dismutase (SOD) activity was defined according to the amount of enzyme in the supernatant that inhibited the rate of nitroblue tetrazolium by $50 \%$ at $560 \mathrm{~nm}$. To determine ASA concentration, each $0.50 \mathrm{~g}$ fresh root sample was homogenized in $5 \mathrm{~mL}$ oxalic acidEDTA solution and centrifuged at $4000 \mathrm{rpm}$ for $10 \mathrm{~min}$ at $4{ }^{\circ} \mathrm{C}$. Then, $1 \mathrm{~mL}$ of supernatant was added to $5 \mathrm{~mL}$ oxalic acid-EDTA solution and $0.5 \mathrm{~mL}$ metaphosphoric-acetic acid, left for $10 \mathrm{~min}$, and supplemented with $1 \mathrm{~mL} \mathrm{5 \%} \mathrm{H}_{2} \mathrm{SO}_{4}$. Then, $2 \mathrm{~mL} \mathrm{5 \%}$ ammonium molybdate solution was added to react, then incubated at $30^{\circ} \mathrm{C}$ for $15 \mathrm{~min}$, and measured at an absorbance of $760 \mathrm{~nm}$ (Sharma et al., 2011).

Transmission electron microscopy (TEM). Preparation of the root tips required placement in glutaraldehyde fixative $(2.5 \%)$ at $\mathrm{pH} 7.2$ for $24 \mathrm{~h}$ under vacuum. After all roots were immersed in the fixative, each sample was rinsed three times in phosphoric acid buffer for at least $1 \mathrm{~h}$. The samples were then treated according to Zhou et al. (2016) to observe and photograph root ultrastructure with a TEM (Hitachi, Japan) at $80 \mathrm{kV}$.

Statistical analysis. Means were compared by Duncan's multiple-range test at the $5 \%$ level of probability by SPSS 19.0 (IBM Corporation, Somers, NY). Plotting was conducted with Origin 9.1 pro (Origin Laboratory, Northampton, MA).

\section{Results}

Root morphological traits. There were no significant differences in morphological traits between two control groups. Total length, surface area, and volume in DS- 8 were $50.6 \%$,
$52.3 \%$, and $52.8 \%$ lower $(P<0.05)$, respectively, than in DS-12 treatment. SRL and SRA exhibited a significantly decreasing pattern from DS-8 to DS- 12 treatment $(P<0.05$, Table 1$)$. Total length, surface area, volume, SRL, and SRA in DS-12 treatment decreased to $27.3 \%, 29.0 \%$, $20.5 \%, 17.7 \%$, and $41.8 \%$ as compared with CK-12 treatment. The root density of DS-12 plants was significantly higher $(P<0.05)$ than those in CK and DS- 8 plants.

Figure 1 showed the proportion of root traits in diametric classes. T. 406 plants maintained a relatively high death rate of roots $>2 \mathrm{~mm}$ in the drought condition. For control plants, root traits were almost constant during the experiment, whereas those in DS-8 and DS-12 treatments gradually changed. Differences between CK-8 and DS-8 treatments were detected in terms of root length, surface area, and volume. In particular, root length, surface area, and volume in DS-12 treatment of the minimum diametric class $(0-1 \mathrm{~mm})$ were always the lowest when compared with CK-12 and DS- 8 treatments. There was more than $53.1 \%$, with the maximum percentage in root length in DS-8 treatment $(98.7 \%)$, in the frequency of root length, surface area, and volume in fine roots in drought-stressed plants.

Root vigor, $\mathrm{RWC}$, proline, $\mathrm{ABA}, \mathrm{H}_{2} \mathrm{O}_{2}$, and antioxidase. Root vigor and RWC were significantly decreased $(P<0.05)$ by drought stress. They were 5.46 and 3.20 times higher in CK-12 treatment than in DS-12 treatment, respectively (Fig. 2A and B). The concentration of proline increased $(P<0.05)$ by $25.0 \%$ in DS-8 treatment than in CK-8 treatment, and no difference was observed among DS-8, CK-12, and DS-12 treatments (Fig. 2C). Compared with CK-8 treatment, ABA concentration was unchanged in DS- 8 treatment. However, in DS-12 treatment, it increased significantly $(P<0.05)$ to $147.2 \mathrm{ng} \cdot \mathrm{g}^{-1}$ (Fig. 2D).

The imposing of drought resulted in significant $\mathrm{H}_{2} \mathrm{O}_{2}$, SOD, and ASA accumulations in T. 406 roots. Compared with CK-8, they increased by $90.0 \%, 13.9 \%$, and $35.5 \%$ $(P<0.05)$, respectively, in DS-8 plants. In DS-12 treatment, the concentration of $\mathrm{H}_{2} \mathrm{O}_{2}$ and activities of SOD and ASA increased significantly (Table 2).

Effect of drought stress on root tip ultrastructure. In CK plants, cells of T. 406 plant roots had smooth and continuous cell membranes and cell walls (Fig. 3A). Mitochondria were easily recognized because of the wider and variable intracellular spaces between them. Besides, endoplasmic

Table 1. Root morphological parameters of T. 406 plants under different treatments.

\begin{tabular}{|c|c|c|c|c|c|c|}
\hline Treatment & Total length (m) & Surface area $\left(\mathrm{cm}^{2}\right)$ & Volume $\left(\mathrm{cm}^{3}\right)$ & $\operatorname{SRL}\left(\mathrm{m} \cdot \mathrm{g}^{-1}\right)$ & SRA $\left(\mathrm{cm}^{2} \cdot \mathrm{g}^{-1}\right)$ & Density $\left(\mathrm{g} \cdot \mathrm{cm}^{-3}\right)$ \\
\hline$\overline{\mathrm{CK}}-8$ & $82.7 \pm 9.1 \mathrm{a}$ & $1253 \pm 22.1 \mathrm{a}$ & $22.9 \pm 1.2 \mathrm{a}$ & $9.03 \pm 1.0 \mathrm{a}$ & $137.6 \pm 2.6 \mathrm{~b}$ & $0.39 \pm 0.04 \mathrm{c}$ \\
\hline DS-8 & $47.8 \pm 3.6 b$ & $726.5 \pm 13.4 \mathrm{~b}$ & $9.26 \pm 1.1 \mathrm{~b}$ & $3.39 \pm 0.3 b$ & $123.1 \pm 3.2 \mathrm{~b}$ & $0.63 \pm 0.05 b$ \\
\hline CK-12 & $86.2 \pm 6.3 \mathrm{a}$ & $1193 \pm 39.2 \mathrm{a}$ & $21.3 \pm 2.1 \mathrm{a}$ & $9.79 \pm 1.1 \mathrm{a}$ & $135.5 \pm 4.3 b$ & $0.41 \pm 0.09 \mathrm{c}$ \\
\hline DS-12 & $23.6 \pm 2.3 \mathrm{c}$ & $346.2 \pm 19.3 \mathrm{c}$ & $4.37 \pm 0.3 \mathrm{c}$ & $1.74 \pm 0.3 \mathrm{c}$ & $56.75 \pm 2.3 \mathrm{a}$ & $1.39 \pm 0.07 \mathrm{a}$ \\
\hline
\end{tabular}

Data are mean \pm SE $(n=4)$. Different small letters within the same column are significantly different at $P<0.05$. SRL $=$ specific root length; SRA $=$ specific root area. 


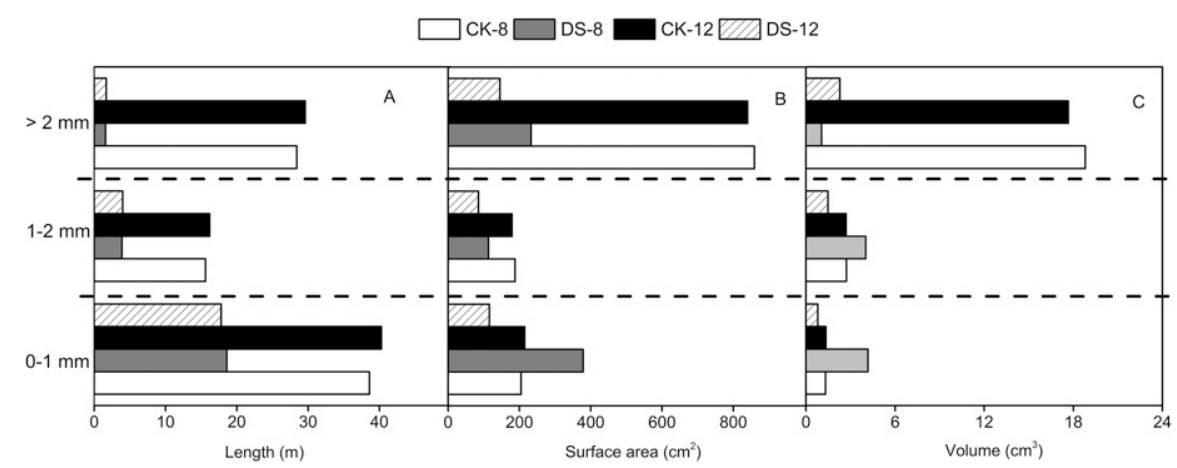

Fig. 1. Total length $(\mathbf{A})$, surface area $(\mathbf{B})$, and volume $(\mathbf{C})$ distribution at diametric classes of $0-1,1-2$, and $>2 \mathrm{~mm}$ of $T .406$ plants under different treatments.

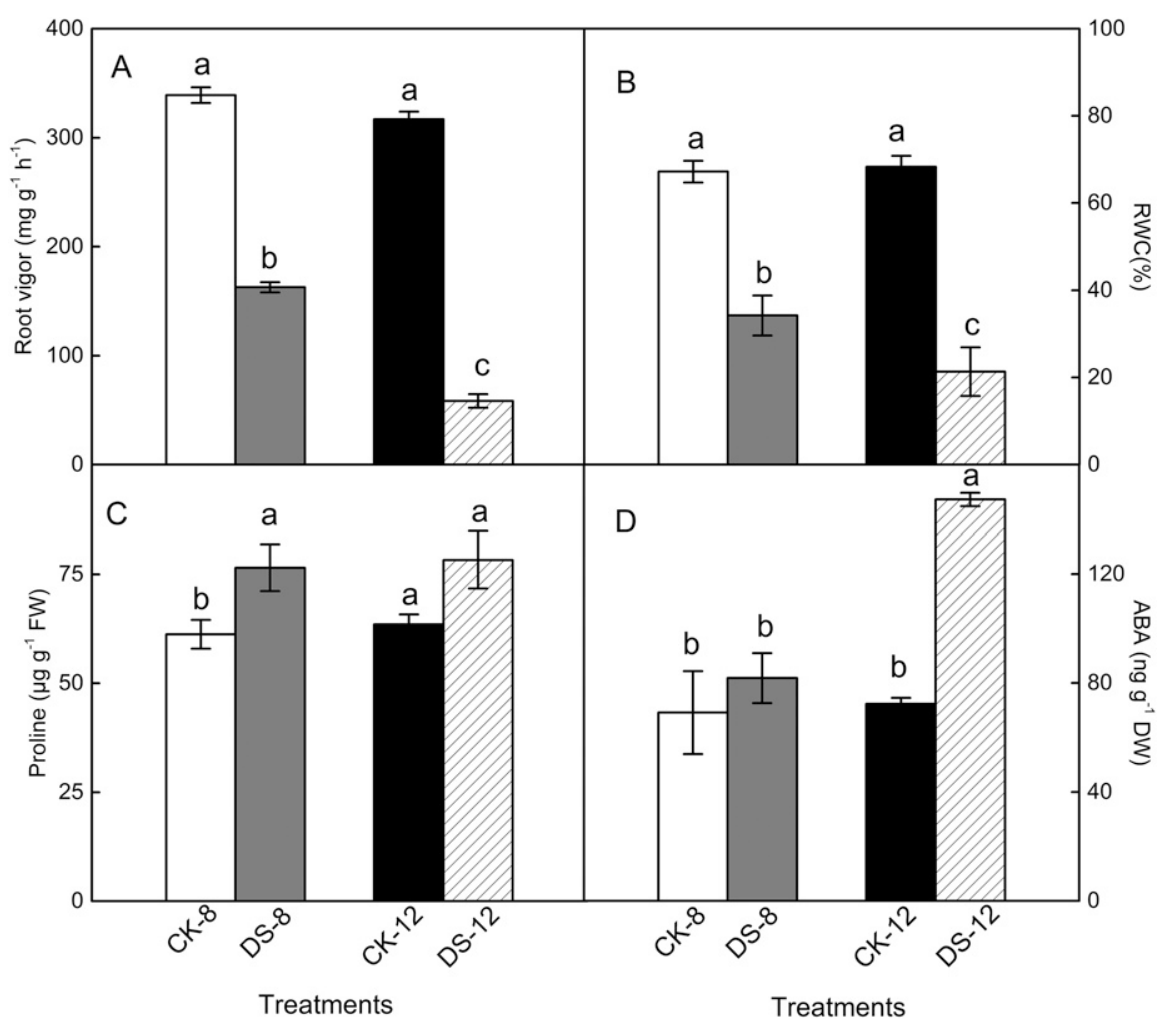

Fig. 2. Root vigor (A), relative water content (RWC, B), proline (C), and abscisic acid (ABA, D) of T. 406 plants under different treatments. Data are mean \pm SE $(n=4)$. Different lowercase letters indicate significant differences $(P<0.05)$.

Table 2. Content of $\mathrm{H}_{2} \mathrm{O}_{2}$ and activity of SOD and ASA in T. 406 plant root under different treatments.

\begin{tabular}{lccc}
\hline Treatment & $\mathrm{H}_{2} \mathrm{O}_{2}$ content $\left(\mu \mathrm{g} \cdot \mathrm{g}^{-1} \mathrm{FW}\right)$ & SOD activity $\left(\mathrm{U} \cdot \mathrm{g}^{-1} \mathrm{FW}\right)$ & ASA activity $\left(\mathrm{mg} \cdot \mathrm{g}^{-1} \mathrm{FW}\right)$ \\
\hline CK-8 & $2.0 \pm 0.4 \mathrm{c}$ & $151.2 \pm 11.1 \mathrm{c}$ & $26.7 \pm 3.1 \mathrm{c}$ \\
DS-8 & $3.6 \pm 1.1 \mathrm{~b}$ & $172.3 \pm 10.6 \mathrm{~b}$ & $36.2 \pm 3.4 \mathrm{~b}$ \\
CK-12 & $2.1 \pm 0.3 \mathrm{c}$ & $141.2 \pm 9.1 \mathrm{c}$ & $25.2 \pm 5.1 \mathrm{c}$ \\
DS-12 & $4.7 \pm 0.3 \mathrm{a}$ & $200.2 \pm 15.3 \mathrm{a}$ & $42.3 \pm 4.3 \mathrm{a}$ \\
\hline
\end{tabular}

Data are mean $\pm \operatorname{SE}(n=4)$. Different small letters within the same column are significantly different at $P<0.05 . \mathrm{H}_{2} \mathrm{O}_{2}=$ hydrogen peroxide; $\mathrm{SOD}=$ superoxide dismutase; $\mathrm{ASA}=$ ascorbic acid; $\mathrm{FW}=$ fresh weight.

reticulums were well arranged (Fig. 3D). However, in DS-8 treatment, the organelle exhibited a dehydrated structure, and we can find a disrupted shape with dim membranes in distinct grana regions (Fig. 3B). Nucleus became considerably swollen. In addition, the envelopes of mitochondria were disrupted. The thylakoid-like organelle was loosened and distorted, beginning to disappear
Root nutrients and growth traits. TN concentration of $T$. 406 roots in DS-12 treatment increased significantly $(P<0.05)$ compared with that in CK-12 and DS- 8 treatments, respectively. The contents of TN were the least $(P<0.05)$ in DS- 8 treatment, mainly attributing to the decreased root biomass and $\mathrm{TN}$ concentration (Table 3 ). TP concentration of $T .406$ roots, ranging between 3.8 and $4.2 \mathrm{mg} \cdot \mathrm{g}^{-1}$, did not change significantly with soil drying. By contrast to root $\mathrm{TN}$ contents, there was no significant difference in TP contents in DS- 8 and CK-12 plants (Table 3 ). At the end of this experiment, significant differences were detected between CK and DS treatments for root biomass, with that of CK- 8 and CK- 12 plants being $\approx 54.2 \%$ and $44.2 \%$ higher $(P<0.05)$ than that of DS-8 and DS-12 plants, respectively. For root/shoot ratio, DS-12 plant was $24.4 \%(P<0.05)$ and $7.1 \%$ higher than CK-12 and DS- 8 plants, respectively (Table 3 ).

\section{Discussion}

Resources are often distributed inhomogeneously in the soil, and, thus, the morphology and physiology of roots are quite crucial for the absorption of soil water and nutrients. Varney and Canny (1993) reported that water absorbed by lateral roots accounted for more than $80 \%$ of the whole root system during the plant growth process. Before this experiment, few references were available describing root morphology and physiology of Taxodium and their relationships with water availability. Our results showed that root length, surface area, and volume of $T .406$ plants exhibited a decreasing pattern during progressive drought. Plant root traits are generally suppressed under dry conditions, and T. 406 root biomass is sensitive to soil drying. This is a result of redistribution of the roots throughout the soil because basal regions of the parental roots are located in a limited space near the plant body (Ito et al., 2006). Under drought stress condition, a significant decrease in root volume would contribute to greater root density, leading to smaller mechanical impedance and greater penetrate capacity when $T .406$ plant roots are elongated. There is a consensus that stronger root vertical growth ability could maximize soil moisture capture and, thus, maintain a high plant water status under resource-limited conditions (Luo, 2010; Zhang et al., 2012). A similar result was obtained in a drought-resistant genotype: Taxodium hybrid 'Zhongshanshan 118' whose root/shoot ratio was increased significantly by progressive drought stress due to the relatively inhibited growth of leaf and stem (Shi et al., 2016).

Pemán et al. (2006) noted that lateral roots became thicker and consumed more energy during the vertical downward growth of taproots; thus, SRL and SRA may be used as a predictor of the benefit (length and area) to investment (DW) ratio of the root system. In DS-8 and DS-12 treatments, the 
frequency of root length, surface area, and volume in fine roots increased, indicating a relatively high death rate of roots $(>2 \mathrm{~mm})$ in the drought condition, whereas SRL and SRA decreased compared with control treatments. This result indicated that $T .406$ plant root patterns generating in a water-deficit condition could be considered as more efficient than that observed in a well-water condition. Following the architecture named 'energy minimization' (Mcculloh and Sperry, 2005), lateral roots in T. 406 plants characterized by less massive roots per unit length or area were capable of maintaining a higher hydraulic conductance. Such responses in the lateral roots might be beneficial for transferring nutrients either from dead roots or aboveground parts (Ito et al., 2006). Evidenced by increased TN concentration and TP contents, the relatively high death rate of roots $(>2 \mathrm{~mm})$ in droughtstressed T. 406 plants might help transfer $\mathrm{N}$ and $\mathrm{P}$ to fine roots.

Generally, plants undergo mild water stress after soil drying for 2-4 d, and then water stress becomes moderate after 6-10 d without irrigation and is considered severe after $12 \mathrm{~d}$ (Hsiao, 1973). Responses of plants to water deficit at the physiological and biochemical level involve various mechanisms, including those for minimizing water loss, scavenging toxic oxygen species, and

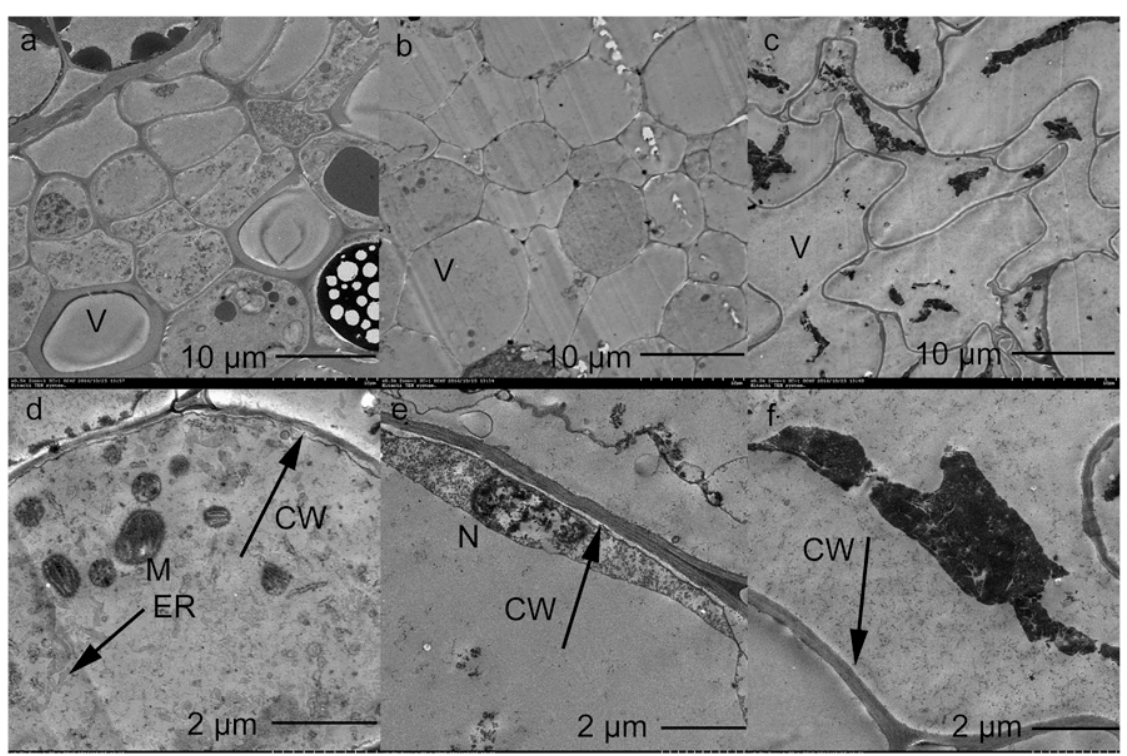

Fig. 3. Effect of drought stress on ultrastructure $(\times 500, \mathbf{A}-\mathbf{C} ; \times 2000, \mathbf{D}-\mathbf{F})$ of $T .406$ plant root tips. (A and D) Root sample of control; (B and $\mathbf{E}$ ) root sample of DS-8; (C and $\mathbf{F}$ ) root sample of DS-12. CW = cell wall; $\mathrm{ER}=$ endoplasmic reticulum; $\mathrm{M}=$ mitochondrion; $\mathrm{N}=$ nucleus; $\mathrm{V}=$ vacuole. keeping cellular stability (Vanaja et al., 2011). In the present study, root RWC in drought-stressed T. 406 plants decreased significantly, and the value of CK-12 treatment was 3.20 times of that in DS-12 treatment. Rampino et al. (2006) stated that water content in plants can be identified by measuring RWC at a particular time point. Thus, nonirrigation has caused part of water loss in T. 406 roots in DS-8 and DS-12 treatments. Water deficit invariably leads to a considerable increase in the cellular antioxidase and then enhances reactive oxygen species, the most important of which is $\mathrm{O}_{2}^{-}$. As the first threshold of enzymatic and nonenzymatic defense, SOD and ASA play a key role in catalyzing the dismutation of $\mathrm{O}_{2}{ }^{-}$into $\mathrm{H}_{2} \mathrm{O}_{2}$. Proline accumulated at the same time to facilitate its hydroxyl groups bonding with hydrogen in water to stabilize critical enzymes and cellular structures (Jones, 1992). Compared with CK-8 T. 406 plants, root SOD and ASA activity increased significantly in DS-8 plants and they kept increasing in DS-12 plants, with proline collaboratively protecting cytoplasmic proteins and cell membranes from desiccation. It has recently been found that the potential activation of 1-pyrroline-5-carboxylate synthetase gene expression probably occurs with proline accumulation in Taxodium plants under drought stress conditions
(Wang et al., 2017). Similar reports of enzymatic and nonenzymatic defense to drought stress had been observed in roots of kentucky bluegrass (Poa pratensis) and wheat (Triticum aestivum) (Bian and Jiang, 2009; Farooq et al., 2013). In addition, after being catalyzed from $\mathrm{O}_{2}^{-}, \mathrm{H}_{2} \mathrm{O}_{2}$ was also reported to act as a signaling molecule, mediating environmental stress responses with ABA (Kong et al., 2016). It was suggested that $\mathrm{ABA}$ and $\mathrm{H}_{2} \mathrm{O}_{2}$ signaling is complicated, encompassing long-distance stomata closure and root hydraulic conductance (Sobotta et al., 2014; Zhang et al., 2006). Thus, pathways of accumulating ABA and $\mathrm{H}_{2} \mathrm{O}_{2}$ in Taxodium plants under drought stress require further confirmation.

Examining changes in root ultrastructure is usually regarded as a convenient and valuable approach to unveil the basic mechanisms under drought circumstance (Zhou et al., 2016). In our study, internal ultrastructure of cells in CK plants had smooth and continuous cell membranes and cell walls with typical mitochondria. However, the organelle structures of $T$. 406 plant root tips were visibly damaged under drought stress. It is noteworthy that superimposed drought stress made nucleus swollen considerably. In DS-12 treatment, all the cells underwent dramatic changes, in which the organelles showed uncommon ultrastructural features of disorganization and disruption. So in T. 406 plant lateral roots, reduced root biomass and activity (as TTC-reducing capacity) were mainly due to dramatic damages at the ultrastructural level. Other reports showed the close relationship between cellular damage and biomass change (Jin et al., 2010; Zhou et al., 2016).

\section{Conclusion}

The present study provides substantial information about lateral root traits of $T$. 406 plants under drought stress. Our result implies that the elongation of lateral roots was sensitive to soil drying, and the benefitto-investment ratio was reduced to enhance the uptake of water and nutrients in response to drought. Meanwhile, water deficit decreased root vigor by causing cellular damages with enhancement in enzymatic and nonenzymatic activities. These traits enable $T$. 406 plants to survive in xeric environments. Therefore, selection of Taxodium hybrids with plastic root morphology is strongly recommended in the future breeding of drought-resistant varieties.

Table 3. Root nutrients and growth traits of $T$. 406 plants under different treatments.

\begin{tabular}{|c|c|c|c|c|c|c|c|}
\hline \multirow[b]{2}{*}{ Treatment } & \multicolumn{2}{|c|}{ Concn $\left(\mathrm{mg} \cdot \mathrm{g}^{-1} \mathrm{DW}\right)$} & \multicolumn{2}{|c|}{ Content (mg) } & \multirow[b]{2}{*}{ Aboveground DW (g) } & \multirow[b]{2}{*}{ Root DW (g) } & \multirow[b]{2}{*}{ Root/shoot ratio } \\
\hline & $\mathrm{TN}$ & TP & $\mathrm{TN}$ & TP & & & \\
\hline$\overline{\mathrm{CK}-8}$ & $15.4 \pm 3.9 \mathrm{~b}$ & $4.2 \pm 0.6 \mathrm{a}$ & $140 \pm 7.6 \mathrm{a}$ & $38.2 \pm 2.6 \mathrm{a}$ & $25.0 \pm 0.2 \mathrm{a}$ & $9.1 \pm 0.6 \mathrm{a}$ & $0.36 \pm 0.02 \mathrm{~b}$ \\
\hline DS-8 & $14.6 \pm 2.4 \mathrm{~b}$ & $3.8 \pm 0.9 \mathrm{a}$ & $86.1 \pm 7.7 b$ & $22.4 \pm 1.9 b$ & $14.0 \pm 0.2 \mathrm{~b}$ & $5.9 \pm 0.4 b$ & $0.42 \pm 0.04 \mathrm{ab}$ \\
\hline CK-12 & $16.4 \pm 2.9 \mathrm{~b}$ & $3.9 \pm 0.6 \mathrm{a}$ & $144 \pm 7.6 \mathrm{a}$ & $34.3 \pm 2.1 \mathrm{a}$ & $25.8 \pm 0.3 \mathrm{a}$ & $8.8 \pm 0.6 \mathrm{a}$ & $0.34 \pm 0.04 b$ \\
\hline DS-12 & $24.3 \pm 1.7 \mathrm{a}$ & $4.0 \pm 0.7 \mathrm{a}$ & $148 \pm 10.6 \mathrm{a}$ & $24.4 \pm 3.3 b$ & $13.6 \pm 0.3 b$ & $6.1 \pm 0.3 \mathrm{~b}$ & $0.45 \pm 0.04 \mathrm{a}$ \\
\hline
\end{tabular}

Data are mean $\pm \mathrm{SE}(n=4)$. Different small letters within the same column are significantly different at $P<0.05 . \mathrm{TN}=$ total nitrogen; TP $=$ total phosphorus; $\mathrm{DW}=$ dry weight. 


\section{Literature Cited}

Allen, C.D., A.K. Macalady, H. Chenchouni, D. Bachelet, N. McDowell, M. Vennetier-Kitzberger, T. Rigling, D.D. Breshears, E.T. Hogg, G. Patrick, R. Fensham, Z. Zhen, C. Jorge, D. Natalia, L. Jong-Hwan, A. Gillian, W. Steven, S. Akkin, and C. Neil. 2010. A global overview of drought and heat-induced tree mortality reveals emerging climate change risks for forests. For. Ecol. Mgt. 259:660-684.

Bates, L., R. Waldren, and I. Teare. 1973. Rapid determination of free proline for water-stress studies. Plant Soil 39:205-207.

Bian, S. and Y. Jiang. 2009. Reactive oxygen species, antioxidant enzyme activities and gene expression patterns in leaves and roots of Kentucky bluegrass in response to drought stress and recovery. Scientia Hort. 120:264-270.

Cavelier, J. 1992. Fine-root biomass and soil properties in a semideciduous and a lower montane rain forest in Panama. Plant Soil 142 (2):187-201.

Creech, D., L. Zhou, Y. Yunlong, and T. EguiluzPiedra. 2011. Can Taxodium be improved? Arnoldia 69:11-20.

Diffenbaugh, N.S. and M. Scherer. 2011. Observational and model evidence of global emergence of permanent, unprecedented heat in the 20th and 21 st centuries. Clim. Change 107:615-624.

Doussan, C., G. Vercambre, and L. Pagès. 1999. Water uptake by two contrasting root systems (maize, peach tree): Results from a model of hydraulic architecture. Agronomie 19:255263.

Farooq, M., M. Irfan, T. Aziz, I. Ahmad, and S.A. Cheema. 2013. Seed priming with ascorbic acid improves drought resistance of wheat. J. Agron. Crop Sci. 199:12-22.

Hardie, M., B. Clothier, S. Bound, G. Oliver, and D. Close. 2014. Does biochar influence soil physical properties and soil water availability? Plant Soil 376(1-2):347-361.

Hartmann, H., H.D. Adams, W.R.L. Anderegg, S. Jansen, and M.J.B. Zeppel. 2015. Research frontiers in drought-induced tree mortality: Crossing scales and disciplines. New Phytol. 205:965-969.

Hsiao, T.C. 1973. Plant responses to water stress. Annu. Rev. Plant Physiol. 24:519-570.

Ito, K., K. Tanakamaru, S. Morita, J. Abe, and S. Inanaga. 2006. Lateral root development, including responses to soil drying, of maize (Zea mays) and wheat (Triticum aestivum) seminal roots. Physiol. Plant. 127:260-267.
Jin, J., G. Wang, X. Liu, L. Mi, Y. Li, Y. Xu, and S.J. Herbert. 2010. Genetic improvement of yield shapes the temporal and spatial root morphology of soybean (Glycine max) grown in north-east China. N. Z. J. Crop Hort. Sci. 38:177-188.

Jones, H G. 1992. Plants and microclimate: A quantitative approach to environmental plant physiology. Cambridge Univ. Press.

Kano, M., Y. Inukai, H. Kitano, and Y. Akira. 2011. Root plasticity as the key root trait for adaptation to various intensities of drought stress in rice. Plant Soil 342(1-2):117-128.

Kirk, P.L. 1950. Kjeldahl method for total nitrogen. Anal. Chem. 22(2):354-358.

Kong, X., Z. Luo, H. Dong, A.E. Eneji, and W. Li 2016. $\mathrm{H}_{2} \mathrm{O}_{2}$ and $\mathrm{ABA}$ signaling are responsible for the increased $\mathrm{Na}^{+}$efflux and water uptake in Gossypium hirsutum L. roots in the non-saline side under non-uniform root zone salinity. J. Expt. Bot. 67:2247-2261

Liu, R.X., Z.G. Zhou, W.Q. Guo, B.L. Chen, and D.M. Oosterhuis. 2008. Effects of N fertilization on root development and activity of waterstressed cotton (Gossypium hirsutum L.) plants. Agr. Water Mgt. 95:1261-1270.

Luo, L.J. 2010. Breeding for water-saving and drought-resistance rice (WDR) in China. J. Expt. Bot. 61:3509-3517.

Mcculloh, K.A. and J.S. Sperry. 2005. Patterns in hydraulic architecture and their implications for transport efficiency. Tree Physiol. 25:257-267.

Mel'Tser, R.A. 1960. Colorimetric method of determining phosphorus in soils and plants. Pochvovedenie 6:103-106.

Pemán, J., J. Voltas, and E. Gil-Pelegrin. 2006. Morphological and functional variability in the root system of Quercusilex L. subject to confinement: Consequences for afforestation. Ann. For. Sci. 63:425-430.

Rampino, P., S. Pataleo, C. Gerardi, G. Mita, and C. Perrotta. 2006. Drought stress response in wheat: Physiological and molecular analysis of resistant and sensitive genotypes. Plant Cell Environ. 29:2143-2152.

Rouphael, Y., M. Cardarelli, G. Colla, and E. Rea. 2008. Yield, mineral composition, water relations, and water use efficiency of grafted mini-watermelon plants under deficit irrigation. HortScience 43:730-736.

Rowland, L. 2015. Death from drought in tropical forests is triggered by hydraulics not carbon starvation. Nature 528:119-122.

Sharma, D.K., A. Dubey, M. Srivastav, A. Singh, R. Sairam, R.A. Pandey-Dahuja, and C. Kaur.
2011. Effect of putrescine and paclobutrazol on growth, physiochemical parameters, and nutrient acquisition of salt-sensitive citrus rootstock Karna khatta (Citrus karna Raf.) under $\mathrm{NaCl}$ stress. J. Plant Growth Regulat. 30:301-311.

Shi, Q., Y. Yin, Z. Wang, W. Fan, and J. Hua. 2016. Physiological acclimation of Taxodium hybrid 'Zhongshanshan 118' plants to short-term drought stress and recovery. HortScience 51:1159-1166.

Sobotta, M.C., W. Liou, S. Stöcker, S. Sarah, T. Deepti, O. Michael, R. Thomas, N.D.S. Annette, and P.D. Tobias. 2014. Peroxiredoxin-2 and STAT3 form a redox relay for $\mathrm{H}_{2} \mathrm{O}_{2}$ signaling. Nat. Chem. Biol. 11(1):64-70.

Vanaja, M., S.K. Yadav, G. Archana, N.J. Lakshmi, P.R.R. Reddy, P. Vagheera, S.K.A. Razak, M. Maheswari, and B. Venkateswarlu. 2011. Response of C4 (maize) and C3 (sunflower) crop plants to drought stress and enhanced carbon dioxide concentration. Plant Soil Environ. 57(5):207-215

Varney, G. and M.J. Canny. 1993. Rates of water uptake into the mature root system of maize plants. New Phytol. 123:775-786.

Wang, Z., F. Yu, Q. Shi, J. Hua, L. Xuan, W. Fan, and Y. Yin. 2017. Cloning and expression analysis of THP5CS and THA-OAT gene in Taxodium hybrid 'Zhongshanshan 407' under drought stress. J. Nanjing For. Univ. 41 (5):191-196 (in Chinese).

Wu, X., W. Xiaoling, S. Wanping, and M. Guicheng. 2016. Preliminary afforestation evaluation of Taxodium Zhongshanshan "405, 406, 407" in Rudong county seawall. J. Fujian For. Sci. Technol. 43(4):62-65 (in Chinese).

Zhang, H., C. Ju, T. Chen, Z. Cao, Z. Wang, and J. Yang. 2012. Effect of water-saving irrigation on the grain yield of water-saving and droughtresistance rice and its physiological bases. Sci. Agr. Sin. 45:4782-4793 (in Chinese).

Zhang, J., W. Jia, J. Yang, and A.M. Ismail. 2006. Role of ABA in integrating plant responses to drought and salt stresses. Field Crops Res. 97:111-119.

Zhou, Q., Y. Wu, Z. Chonglan, X. Xing, L. Liu, H. Jiang, and H. Xing. 2016. Triadimefon induced $\mathrm{C}$ and $\mathrm{N}$ metabolism and root ultra-structural changes for drought stress protection in soybean at flowering stage. J. Plant Growth Regulat. 35:222-231. 